\title{
Usos portuários ou correlatos na área urbana do município de Paranaguá-PR
}

Port or related uses in the urban area of the municipality of Paranaguá-PR

Usos portuarios o afines en el área urbana del municipio de Paranaguá-PR

\author{
Kaline Ribeiro de Freitas \\ Geógrafa, IFPR, Brasil. \\ Kaly_rib@hotmail.com
}

Emerson Luis Tonetti Professor Doutor, IFPR-Paranaguá, Brasil. emerson.tonetti@ifpr.edu.br 


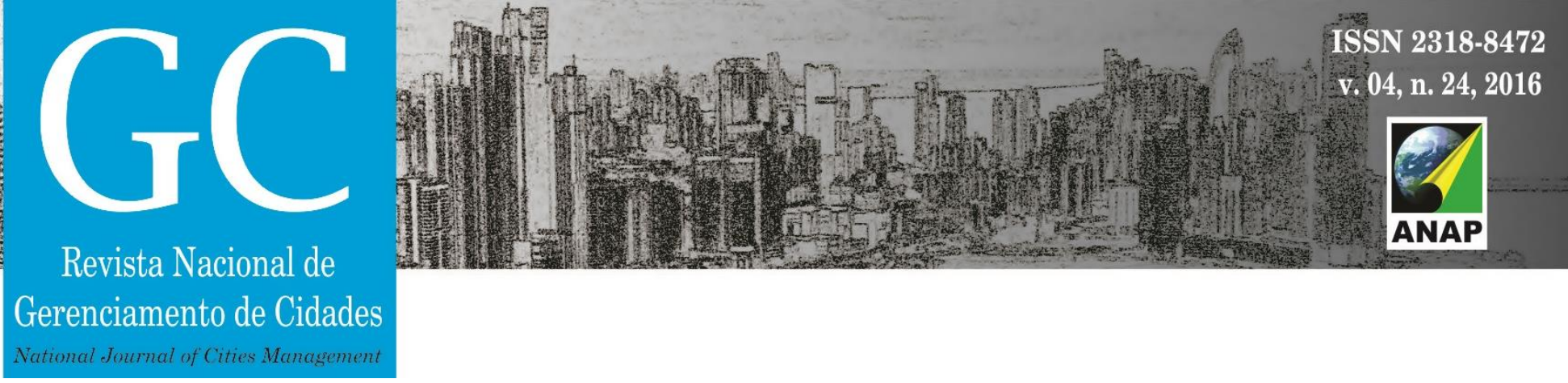

\title{
RESUMO
}

Com a crescente urbanização do município e sua localização, que garante acesso tanto pelo mar como por rodovias, Paranaguá, se destaca pela presença do Porto Dom Pedro II em sua área urbana. Essa interação entre os usos, influencia o crescimento urbano local, com alterações da qualidade ambiental. Mediante essa vulnerabilidade urbana, o estudo visa identificar, dentre os usos com alto potencial de causar poluição, quais são os usos portuários ou correlatos, e evidenciar se a distribuição desses usos configura incompatibilidade e/ou inconveniência em relação a Zona de Interesse Portuário (ZIP) e a Zona de Requalificação Urbana (ZRU) no município de Paranaguá. O levantamento de dados foi realizado in loco, utilizando a carta base municipal e tendo como apoio o software Google Earth. Para a produção da carta de distribuição dos usos portuários ou correlatos foi utilizado o software AutoCAD, em rotinas de geoprocessamento. Constatou-se que há usos portuários ou correlatos na ZRU, principalmente nas proximidades da linha que delimita o fim da ZRU e o início da ZIP, caracterizando a inconveniência e/ou incompatibilidade conforme discriminam as finalidades da ZRU, presentes no plano diretor municipal. Da mesma forma, foram evidenciadas ilhas de habitação inseridas na Zona de Interesse Portuário, caracterizando, a inconveniência e/ou incompatibilidade conforme discriminam as finalidades da ZIP, presentes no plano diretor municipal.

PALAVRAS-CHAVE: Qualidade Ambiental Urbana. Usos portuários ou correlatos. Planejamento da Paisagem.

\begin{abstract}
With the increasing urbanization of the city and its location, which ensures access to both by sea and by road, Paranagua, stands out for Porto Dom Pedro II's presence in its urban area. This interaction between uses, influences the local urban growth, changes in environmental quality. Through this urban vulnerability, the study aims to identify those uses with high potential to cause pollution, which are the port or related uses, and show the distribution of these uses sets mismatch and / or inconvenience regarding Port Interest Zone (ZIP) and the Urban Renewal area (ZRU) in the municipality of Paranaguá. Data collection was carried out on site, using the letter municipal basis and to support the Google Earth software. For the production of letter distribution port or related uses AutoCAD software was used in GIS routines. It was found that port uses or related in ZRU, especially near the line that delineates the end of ZRU and early ZIP, featuring the inconvenience and / or incompatibility as discriminating against the purposes of ZRU present in municipal director plan. Similarly, housing islands were shown inserted in the Port of Interest Zone, featuring the inconvenience and / or incompatibility as discriminating against ZIP purposes, present in municipal director plan.
\end{abstract}

KEYWORDS: Urban environmental quality. Port or related uses. Landscape Planning.

\section{RESUMEN}

Con la creciente urbanización de la ciudad y su ubicación, lo que garantiza el acceso tanto por mar y por tierra, Paranagua, se destaca por la presencia Puerto Dom Pedro II en su región urbano. Esta interacción entre los usos, influye en el crecimiento pueblo ubicación, los cambios en la calidad ambiental. Con esta debilidad urbano, el estudio tiene como meta apontar los usos con alto capacidad de causa contaminación, que son el puerto o usos afines, y mostrar la distribución de estos usos establece desajuste y/o inconvenientes con respecto a Zona de Interés Puerto (ZIP) y el Zona de Recalificación Urbano (ZRU) en el condado de Paranagua. La recolección de datos se llevó a cabo en el lugar, utilizando la base municipal carta y para apoyar el software Google Earth. Para la producción de puerto de distribución y relacionados utiliza el software AutoCAD se utiliza en las rutinas de SIG. Se encontró que hay usos relacionados con el puerto en ZRU, especialmente en la proximidad de la línea que delimita el final de ZRU y primero del ZIP, con los inconvenientes y/o incompatibilidad discriminatorias respecto de los efectos de la presente ZRU en el plan director municipal. Del mismo modo, las islas de vivienda, se mostró insertados en el Puerto de Zona de Interés, con los inconvenientes y/o incompatibilidad discriminatorias respecto de los propósitos ZIP, presentes en el plan director municipal.

PALABRAS CLAVE: Calidad del medio ambiente urbano. Puerto o usos afines. Planificación del Paisaje. 


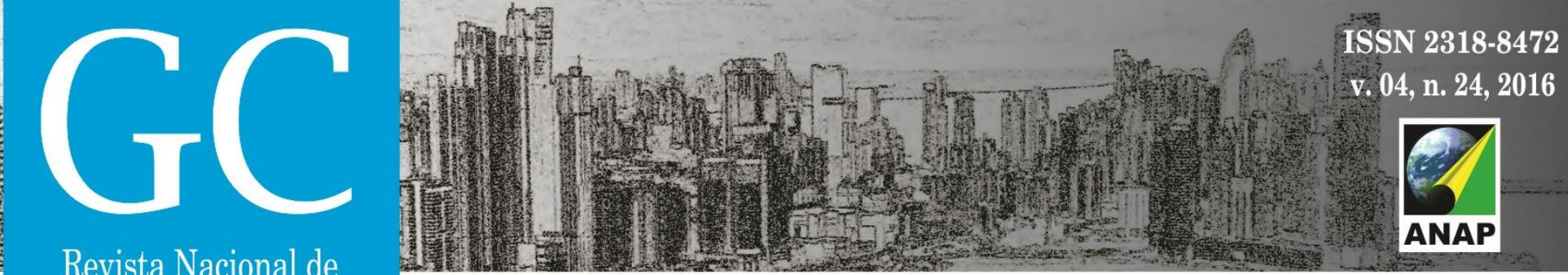

Gerenciamento de Cidades

regulamentando o uso da propriedade urbana em benefício do interesse público, da segurança e do bem-estar dos cidadãos, bem como do equilíbrio ambiental.

Com o efeito do Estatuto da Cidade Lei que estabelece ao Município o adequado ordenamento territorial, mediante ao planejamento e controle de uso, do parcelamento e da ocupação do solo, evidenciando a competência municipal para que sejam adotadas medidas que favoreçam o desenvolvimento da região, seja na área da sustentabilidade, política, cultural, econômica, ambiental e institucional, ou seja, sendo responsável em formular a política urbana e fazê-la cumprir através do Plano Diretor as funções sociais da cidade, permitindo e garantindo o acesso e direito de todos que nela habitam (BRASIL, 2001).

Estatuto da Cidade prevê em seu Art 2, inciso IV, o planejamento do desenvolvimento da cidade para o ordenamento e controle do uso do solo, como forma de evitar usos incompatíveis e inconvenientes (BRASIL, 2001).

De acordo com Araujo 2003, Para corrigir a desordem da crescente urbanização e consequentemente os pontos negativos ao meio ambiente, a distribuição espacial deve ser planejada, com o intuito de evitar problemas com usos inadequados dos imóveis urbanos, sua proximidade quanto aos usos incompatíveis e inconvenientes, considerando a poluição, degradação ambiental e a deterioração das áreas urbanas, é nesse contexto que a forma utilizada do uso do solo visa estabelecer ordem e controle em seu planejamento.

Desta forma, o Estatuto da Cidade procura garantir que o crescimento e o desenvolvimento das cidades sejam processos que contribuam para o equilíbrio social e ambiental e neste sentido, as práticas de planejamento, como o zoneamento urbano e suas diretrizes, são essenciais para entender a distribuição dos usos portuários ou correlatos no município de Paranaguá. Visto que, o município historicamente não teve o devido planejamento urbano para distanciar esses usos e hoje enfrenta inúmeras dificuldades que podem representar as incompatibilidades e inconveniências citadas na referida lei.

Segundo Pietro 2006, o crescimento muitas vezes desordenado gera degradação ao meio ambiente, necessitando assim de planejamento quanto as ações de desenvolvimento urbano e ambiental.

Para o autor, a instrumentalização do zoneamento ambiental visa ordenar e controlar o uso do solo evitando entre outras questões a utilização inadequada dos imóveis urbanos, a proximidade de usos incompatíveis ou inconvenientes, o uso excessivos ou inadequados em relação à infraestrutura urbana, a instalação de empreendimentos ou atividades que possam funcionar como pólos geradores de tráfego, sem a previsão da infraestrutura correspondente, a deterioração das áreas urbanizadas, a poluição e a degradação ambiental.

Considerando a Lei Complementar no 62 do Plano Diretor da Cidade, o zoneamento urbano corresponde à área urbana do município que apresenta diferentes graus de consolidação e infraestrutura básica instalada, destina-se a concentrar o desenvolvimento e o adensamento urbano. Para tanto, essa lei divide o território urbano do Município de Paranaguá em zonas e 


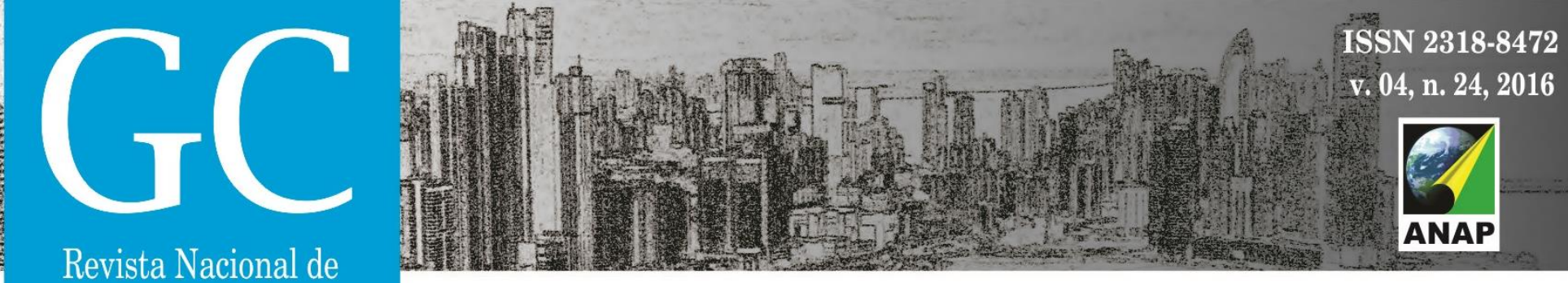

Gerenciamento de Cidades

\section{DELIMITAÇÃO DA ÁREA DE ESTUDO}

O litoral paranaense é constituído por uma estreita faixa montanhosa afundada por falhamentos, que originam a Serra do Mar. É um litoral de imersão, onde antigos vales e enseadas foram preenchidos por sedimentação marinha e terrestre. O relevo é muito suave, com pequenas ondulações e altitudes, que somam alguns metros acima do nível do mar. São comuns os morros isolados e espigões, que se destacam na topografia ou formando pequenos maciços na planície sedimentar (MAACK, 1968).

Conforme estudos do Pró-Atlântica (PIRES et al, 2005), a complexidade geológica litorânea colabora para a formação de solos bastante diversificados, com o predomínio de cambissolos, latossolos, argissolos, organossolos e neossolos litológicos, além de afloramento rochosos em áreas extremamente íngremes.

A vegetação da região de acordo com o IBGE 2010, classifica-se como floresta Ombrófila Densa, fazendo parte do bioma da Mata Atlântica, apresentando também uma parcela de refúgios vegetacionais, associados a solos hidromórficos.

No Programa de Proteção da Floresta Atlântica (PIRES et al, 2005) cobertura vegetal caracteriza-se como: Floresta Ambrófila Densa, Floresta Ombrófila Mista, Áreas de Formação Pioneira, Vegetação Secundária e Refúgios Vegetacionais.

A Serra do Mar constitui barreira natural para os ventos regulares que sopram do oceano e a umidade desses ventos se condensam na vertente da serra, provocando a chuva orográfica nas encostas a leste da Serra, onde são registrados altos índices pluviométricos (PARANÁ, 2006).

Especificamente, a presente área de estudo localiza-se em parte do centro urbano consolidado do Município de Paranaguá, no litoral do Paraná, cuja delimitação urbana é de 95,15 km² e o local de estudo possui 11,64 km2, conforme figura 1 (TONETTI, 2011). 


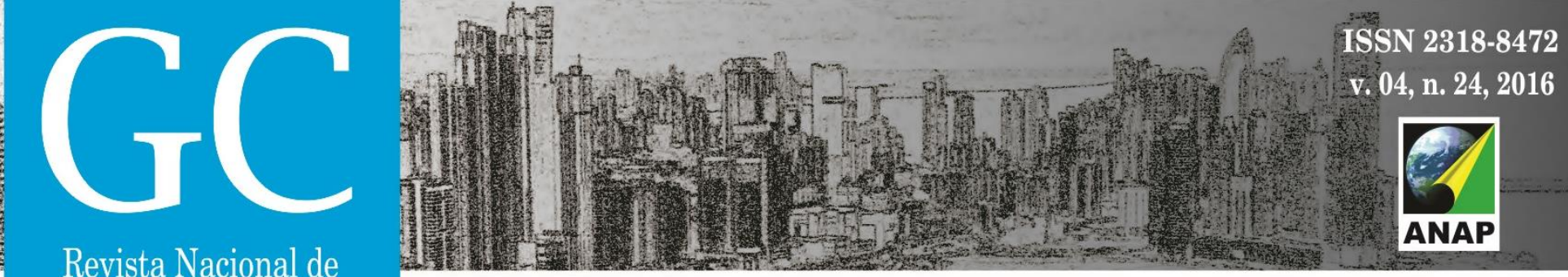

Gerenciamento de Cidades

National Journal of Cities Management

levantamento in loco, identificar na classificação dos usos com maior potencial de causar poluição quais são e qual é a distribuição dos usos portuários ou correlatos na área de estudo. Para identificação dos dados, foi considerada a verificação avistada da calçada/rua somente, sem acessos ao interior desses usos. Para locais de difícil acesso foi utilizado como forma de ferramenta na contribuição do estudo o software gratuito Google Earth.

As informações obtidas foram georreferenciadas, em procedimentos de rotina, no software AutoCAD para apreciação dos resultados da distribuição dos usos portuários ou correlatos na delimitação das Zonas de Requalificação Urbana e de Interesse Portuário.

\section{RESULTADOS E DISCUSSÃO}

$\mathrm{Na}$ área de estudo observa-se que a maior concentração dos usos portuários ou correlatos, que apresentam maior potencial de causar poluição, encontram-se no interior dos limites da Zona de Interesse Portuário (ZIP), abrangendo grande parte desta área e tendo sua maior continuidade na porção norte (Figura 3). Nota-se também que os usos portuários ou correlatos, estendem-se pela região noroeste, central e sul da área de estudo. Nessa região constata-se uma grande faixa contínua de uso residencial (Figura 2) inserida na ZIP.

Essa faixa residencial contínua já existia por ocasião da elaboração do plano diretor em 2007. Percebe-se a potencialidade dos conflitos do uso residencial com o portuário ou correlato na ZIP. Essa área, pela densidade populacional e histórico de ocupação merece destaque por ocasião da revisão do plano diretor para readquirir o status de ZRU. 
municipal. Da mesma forma, foram evidenciadas ilhas de habitação inseridas na Zona de Interesse Portuário, caracterizando, a inconveniência e/ou incompatibilidade conforme discriminam as finalidades da ZIP, presentes no plano diretor municipal.

Diante das constatações citadas se recomenda novos estudos para detalhar e entender melhor as relações estabelecidas entre os usos presentes nas referidas zonas e estender para as demais. Principalmente, a relação com a proximidade entre as zonas, sugere-se a implantação de faixas de transição que atuariam regulando a alteração dos usos entre uma e outra zona.

Conforme considerações do plano diretor municipal, o zoneamento deve proporcionar melhores condições ambientais e de vida para o cidadão na moradia e no trabalho (PARANGUÁ, 2007, LC no 62, Cap. 1 Art 3).

Assim, para a futura revisão do plano diretor, pode-se considerar as informações encontradas no estudo, que desconfiguram a própria Lei estabelecida na cidade de Paranaguá, ou seja, revelar os usos portuários ou correlatos com alto potencial de causar poluição, inseridos na zona de requalificação urbana, assim como usos urbanos (comunidade) inseridos dentro da zona de interesse portuário.

\section{REFERÊNCIAS}

BRASIL. Lei no 10.257 de 10 de julho de 2001. Regulamenta os artigos 182 e 183 da Constituição Federal, estabelece diretrizes gerais da política urbana e dá outras providências. Disponível em: http://www.planalto.gov.br/ccivil_03/leis/LEIS_2001/L10257.htm. Acesso: 02/05/2016.

FÁVERO, O. A. Paisagem e sustentabilidade na bacia hidrográfica do rio Sorocaba (SP). 330p. Tese (Doutorado em Geografia Humana) - Faculdade de Filosofia, Letras e Ciências Humanas da Universidade de São Paulo, São Paulo, 2007. Disponível em: http://www.labs.ufpr.br/site/ Acesso: 14/05/2016

IBGE. Instituto Brasileiro de Geografia e Estatística. Contagem da População 2010. Disponível em: http://ibge.gov.br/cidadesat/xtras/pesqmun.php?pesqmun=densidade+demografica+de+paranagua\&lang=_PT Acesso: 14/05/2016.

MAACK R. Geografia Física do Paraná. Curitiba: BADEP, UFPR,1968.

MONTEIRO, C. A. F.. Geossistemas: a História de uma Procura. São Paulo: Contexto, 2000.

$\mathrm{NUCCI}$, J. C. Qualidade Ambiental e Adensamento Urbano: um estudo de ecologia e planejamento da paisagem aplicado ao distrito de Santa Cecília (MSP). Curitiba: Edição do autor, 2008 (2a ed.). 142p. Disponível em www.geog.ufpr.br/laboratorios/labs/?pg=publicacoes-php Acesso em 15 dezembro 2008.

PARANÁ. Atlas Geomorfológico do Estado do Paraná: Minerais do Paraná. Universidade Federal do Paraná. Curitiba, 2006.

PARANAGUÁ. Lei Complementar 62 de 27 agosto de 2007. Institui o zoneamento de uso e ocupação do solo, com objetivo de orientar e ordenar o crescimento da cidade. Disponível em: http://www.paranagua.pr.gov.br/conteudo/transparencia/plano-diretor . Acesso: 01/07/2016. 
PIRES, P. T. L.; ZILLI A. L.; BLUM C. T. Atlas da Floresta Atlântica do Paraná. Curitiba: SEMA; Programa de Proteção Floresta Atlântica; Pró Atlântica, 2005.

PIETRO, C. E. Estatuto da Cidade e o Meio Ambiente. In: IV Congresso Brasileiro de Direito Urbanístico, São Paulo, 05 a 09 de dezembro de 2006. Disponível em: http://docplayer.com.br/6451085-O-estatuto-da-cidade-e-o-meioambiente.html. Acesso: 10/06/2016.

RICOBOM, A. E. Metodologia Auxiliar para revisão de Planos Diretores Municipais através da Aplicação da Cartografia Prospectiva - Estudo de Caso - Perímetro Urbano de Paranaguá. Tese (Doutorado) - Setor de Ciências da Terra, Universidade Federal do Paraná, Curitiba. 2011. Disponível em: file://C:/Users/d1651282/Downloads/R\%20-\%20T\%20-\%20ARNALDO\%20EUGENIO\%20RICOBOM\%20(1).pdf Acesso em: 12 abril 2015.

TONETTI, E. L. Potencialidades de adensamento populacional por verticalização das edificações e qualidade ambiental urbana no município de Paranaguá, Paraná, Brasil. 235f. Tese (Doutorado) - Setor de Ciências da Terra, Universidade Federal do Paraná, Curitiba. 2011. Disponível em http://200.17.203.155/index.php?codigo_sophia=285569. Acesso em 12 abril 2015. 